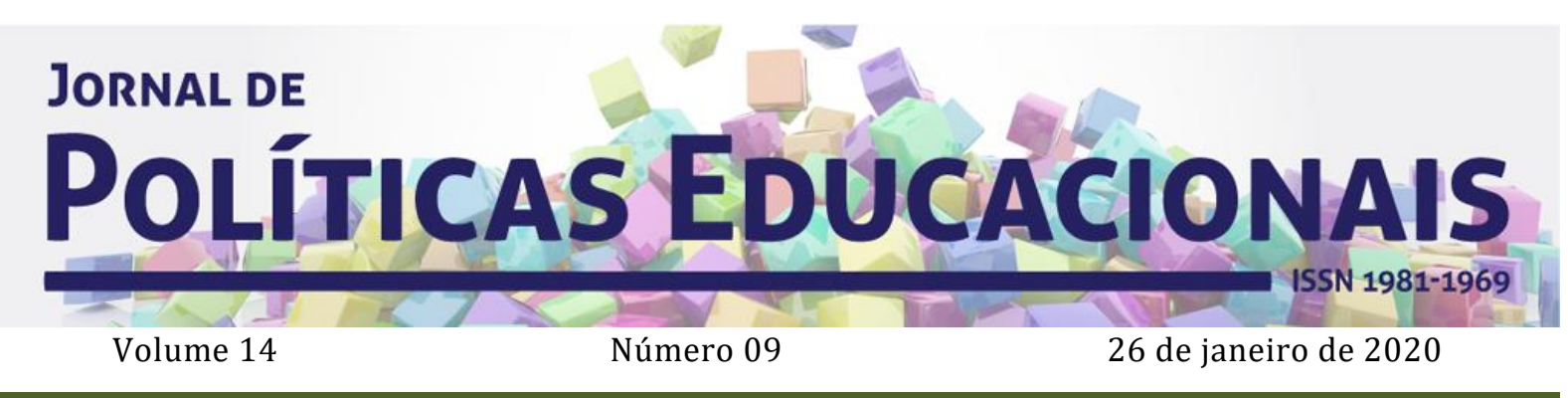

\title{
Variabilidade das despesas das universidades federais no período de 2012 a 2017
}

\section{Variability of federal universities expenses from 2012 to 2017}

\section{Las variaciones de los gastos federales universitarios de 2012 a 2017}

\author{
Lincon Rodrigues Dias Simões ${ }^{1}$ \\ Marcos Antônio Martins Lima
}

Citação: SIMÕES, L. R. D; LIMA, M. A. M. Variabilidade das despesas das universidades federais no período de 2012 a 2017. Jornal de Políticas Educacionais. V. 14, n. 09. Janeiro de 2020.

\section{Resumo}

Esta pesquisa buscou investigar a variabilidade na execução da despesa das 63 universidades federais brasileiras. Para este fim, foi realizada uma análise com dados de 2012 a 2017, extraídos do Tesouro Gerencial. Observou-se que há variações significativas na despesa executada, cujas médias são distorcidas pela presença de outliers. Conclui-se que as análises sobre as despesas das universidades federais devem sempre considerar a heterogeneidade desse conjunto de instituições, pois valores médios para esse conjunto não são representativos, em razão do alto grau de dispersão dos dados.

Palavras-chave: universidades federais, heterogeneidade, despesas.

\begin{abstract}
The present study investigated the variability of the budgetary expenses in the 63 Brazilian federal universities. To do so, an analysis of the primary data, between 2012 and 2017, available from the Tesouro Gerencial, was carried out. The results revealed significant variations in the spending, whose averages are

\footnotetext{
${ }^{1}$ Mestre em Políticas Públicas e Gestão da Educação Superior (UFC). Contador do Instituto Federal de Educação, Ciência e Tecnologia do Ceará (IFCE). Fortaleza, Ceará. Orcid: https://orcid.org/0000-00015321-6188. E-mail: lincolnsimoes@ifce.edu.br

2 Doutor em Educação pela Universidade Federal do Ceará (UFC). Pós-Doutor em Gestão pela Universidade Federal do Rio Grande do Norte (UFRN). Professor Associado na Universidade Federal do Ceará (UFC), Faculdade de Educação e Programa de Pós-graduação em Educação (PPGE). Fortaleza, Ceará. Orcid: http://orcid.org/0000-0001-5541-6220. E-mail: marcos.a.lima@terra.com.br.
} 
distorted by the outliers. It is concluded that analyzes of these expenses must take into account the heterogeneity of the federal universities, since average values for this set are not representative, due the high degree of data dispersion.

Keywords: Brazilian federal universities, heterogeneity, expenses.

\section{Resumen}

En esta investigación se buscó examinar la variabilidad de los gastos de las 63 universidades federales brasileñas. Para lograr este objetivo, se ha realizado un análisis de los datos de 2012 hasta 2017, procedentes del Tesouro Gerencial. Se observa que existen variaciones significativas en los gastos, cuyas medias son distorsionadas por valores atípicos. Se concluye que los análisis sobre los gastos de las universidades federales deben tener en cuenta la heterogeneidad de las instituciones, ya que los valores medios no son representativos, debido al alto grado de dispersión de los datos.

Palabras clave: universidades federales, heterogeneidad, gastos.

\section{Introdução}

As dificuldades financeiras em meio às demandas por expansão e por diversificação de estruturas institucionais foram elencadas pela UNESCO como as principais tendências dos sistemas e instituições de ensino superior: "a limitação dos fundos públicos é um dos maiores freios no processo de mudança e desenvolvimento em ensino superior. É também uma das fontes da crise atual e das tensas relações entre o Estado e a comunidade acadêmica" (UNESCO, 1999, p. 14). No Brasil, as políticas de expansão quantitativa, interiorização e democratização do acesso, ocorridas nos últimos anos $^{3}$, implicaram em grandes desafios para a gestão das Instituições Federais de Educação Superior (IFES), uma vez que tais políticas devem se fazer acompanhar, além dos investimentos em infraestrutura para atender a expansão, de ações voltadas para a assistência estudantil, a fim de viabilizar as condições de permanência e o apoio à formação acadêmica:

Se nos anos recentes o problema do acesso à educação superior foi praticamente superado do ponto de vista da oferta de vagas, por outro lado ainda persiste o problema da permanência, ou seja, a dificuldade de os estudantes permanecerem estudando (CNE; UNESCO, 2012, p. 21).

Assim, as limitações que se impuseram às IFES desde a crise que acometeu a economia brasileira em meados desta década ameaçam, além da manutenção de suas atividades, o próprio processo de mudança social, no que se refere à elitização do ensino superior nessas instituições. De modo que, em vista do preocupante quadro que se

\footnotetext{
${ }^{3}$ Tais políticas, a exemplo da Lei $\mathrm{n}^{\circ} 12.711$, de 29 de agosto de 2012, que determina que $50 \%$ das vagas sejam ofertadas aos alunos das escolas públicas, fizeram emergir um novo perfil do alunato nas IFES: menos elitista, oriundo de extratos da sociedade antes impossibilitados de adentrar nas universidades públicas, conforme constata Ristoff (2014)
} 
desenha para o financiamento da educação superior nos próximos anos, considerando as limitações como as da Emenda Constitucional 95/20164 ou como os contingenciamentos, que se fizeram constantes nos últimos anos, mostra-se relevante a discussão sobre as despesas executadas por essas instituições na atual conjuntura. Esta investigação pretende contribuir para tal discussão ao tempo em que se insere no contexto de um projeto de pesquisa, em curso, que visa estudar as relações entre as despesas das IFES e os seus resultados institucionais.

Buscou-se verificar se há variações significativas na execução da despesa em virtude da heterogeneidade do conjunto das IFES. Parte-se de uma reflexão, de caráter epistemológico, sobre a contabilização da despesa pública e sobre as abordagens já utilizadas na análise dos gastos das universidades federais. Em seguida, realiza-se análises sobre o resultado das despesas executadas pelas IFES, entre 2012 e 2017, com o intuito de investigar a variabilidade dos dados, a fim de verificar se sua dispersão inviabiliza, ou não, a obtenção de valores médios como representativos para o conjunto das IFES.

Destaque-se que pesquisas sobre a execução orçamentária das IFES, quando tomadas em conjunto, são escassas. Sobretudo devido às dificuldades na obtenção das informações:

Cabe-nos comentar que esses dados são fornecidos pelas próprias instituições e, portanto, não há a garantia de que eles correspondam aos valores reais. De qualquer forma, na falta de outras fontes, eles nos fornecem uma primeira aproximação de um universo ainda pouco conhecido (CHAVES; AMARAL, 2015, p. 106).

Ao analisar a evolução das despesas por aluno nas instituições da rede federal de educação profissional e tecnológica (RFEPT), ressalta-se que há uma "completa inexistência de análises dessa natureza na literatura" (PEREIRA, 2019, p. 332). Decerto, no caso das universidades, podem ser encontrados vários estudos sobre modelos de apuração de custos- Contudo, quando se trata da aplicação dessas metodologias, os resultados fornecem uma perspectiva fragmentada do ensino superior em nível federal, uma vez que têm se limitado a uma única, ou a um pequeno número de instituições (ou mesmo a unidades específicas, como departamentos acadêmicos, bibliotecas ou

\footnotetext{
${ }^{4}$ A Emenda Constitucional 95/2016 institui um teto para os gastos públicos com base na despesa primária (exceto, portanto, a despesa com juros) paga no ano de 2016, a vigorar por 20 anos, atualizada anualmente pelo IPCA.
} 
restaurantes universitários ${ }^{5}$ ); o que torna raras pesquisas como esta, que abrangem o conjunto das IFES, a fim de fornecer um panorama atual da realidade das universidades federais brasileiras, no que se refere à aplicação dos recursos que dispõem.

\section{Sobre a execução da despesa pública}

O objeto "despesas das IFES" resulta das atividades desenvolvidas por essas instituições, representando, juntamente com as receitas, a expressão monetária das variações patrimoniais ocorridas no processo de disponibilização de serviços prestados à sociedade. À contabilidade cabe registrar, processar e comunicar a ocorrência de tais variações, de modo que, segundo Hendriksen e Breda (1999, p. 93), o objetivo da contabilidade, de "fornecer informação financeira confiável", direciona-se, sob um enfoque pragmático, para "usuários que visem a tomada racional de decisões" (HENDRIKSEN; BREDA, 1999, p. 93).

Quando tais usuários não são externos (investidores ou credores), mas fazem parte da organização, o uso de informações contábeis associa-se a finalidades gerenciais. Nesse sentido, são especialmente relevantes os dados fornecidos pela contabilidade de custos, "o ramo da contabilidade que mede, registra e relata informações sobre custos" (MAHER, 2001, p 38), cujas funções precípuas são o auxílio ao controle e à tomada de decisões. Com dados do custo de produção, pode-se estabelecer padrões, orçamentos, fixar preços de venda, estimar consequências sobre medidas de corte de produtos e de opções de compra ou fabricação etc. Enfim, a contabilidade de custos subsidia o aperfeiçoamento dos processos de produção ao "identificar atividades que não adicionam valor, mas consomem recursos, e a redesenhar métodos de produção eventualmente caros, economizando dinheiro para suas companhias" (MAHER, 2001, p. 51).

Nas organizações públicas brasileiras, os dados que a contabilidade fornece aos usuários externos (cidadãos), para fins de prestação de contas via Portal da Transparência são os mesmos usados para fins internos (controle e tomada de decisão). Isto porque ainda não foi totalmente implantada uma contabilidade de custos no setor

\footnotetext{
${ }^{5}$ Peñazola (1999) desenvolveu uma metodologia que visa estimar os custos em instituições de ensino superior, aplicando-a à Universidade de São Paulo; Peter et al (2003) propuseram um sistema de custos para as universidades federais brasileiras fundamentado no método Activity Based Costing (ABC), que teve uma aplicação piloto na Universidade Federal do Ceará (UFC); Silva, Morgan e Costa (2004), partindo de um estudo de caso realizado na Universidade de Brasília (UNB), também propuseram uma metodologia a fim de determinar o custo do ensino na educação superior.
} 
público. O Sistema Integrado de Administração Financeira do Governo Federal (SIAFI) foi originalmente concebido para operacionalizar a execução do orçamento e não como sistema gerencial, apto a fornecer informações sobre custos. Isso significa que a partir do SIAFI não é possível saber quanto custa determinado serviço (o custo de uma pesquisa, de um curso, ou o custo por aluno), mas apenas quanto o órgão executou, em termos de orçamento, na realização de todo o conjunto de suas atividades.

Portanto, devido à "atual fragilidade da contabilidade, ainda muito influenciada pelo controle do orçamento em detrimento do controle do patrimônio". (MACHADO; HOLANDA, 2010, p. 806) a informação produzida pelo SIAFI não pode ser tida como custo sem a realização de ajustes "transformando a despesa em custo" (MACHADO; HOLANDA, 2010, p. 814). Isto porque o processo de execução da despesa orçamentária não contempla aspectos quantitativos e porque "a geração de informações de custos pressupõe a adoção do regime de competência. Enquanto a contabilidade governamental não adotar na sua plenitude o regime de competência serão necessários os ‘ajustes contábeis'” (MACHADO; HOLANDA, 2010, p. 799).

A esta altura é preciso exemplificar a impropriedade de se considerar a despesa registrada no SIAFI como custo: tecnicamente, a aquisição de material de consumo para um laboratório não representa um custo dos serviços prestados enquanto não houver o consumo desse material nas atividades do laboratório. Sem um sistema de custos apto a informar o consumo de insumos no processo produtivo, a única alternativa é adotar os dados registrados no SIAFI. Contudo, ao proceder desta forma, por uma questão de rigor conceitual, não se deveria denominar como "custo" tais dados. Uma definição mais apropriada seria "gasto", ou, melhor ainda, "despesa”, uma vez que esta é a denominação usada no SIAFI e à qual a legislação sobre finanças públicas se refere constantemente.

\subsection{A problemática do estágio da despesa}

Outro ponto fundamental refere-se ao que vem a ser "despesa registrada no SIAFI", uma vez que a Lei 4.320/64 estabelece três estágios para a contabilização da despesa pública: empenho, liquidação e pagamento.

No empenho reserva-se o recurso, deduzindo-o do orçamento disponível, por meio da emissão de uma nota de empenho em nome do credor. Com isso, a administração garante que, se o bem ou serviço for entregue, há recurso para atender tal fim. Quando o 
fornecedor entrega o objeto do empenho à administração, inicia-se a fase da liquidação: a Nota Fiscal/fatura é lançada no SIAFI, "dando baixa" no empenho e demandando o recurso financeiro para a fase seguinte: a realização do pagamento.

Isto significa que a despesa empenhada não representa a "materialização" dos bens e serviços adquiridos: notas de empenho podem ser canceladas e empenhos inscritos em restos a pagar (que passaram de um ano para outro sem terem sido pagos) podem ser anulados (caso o fornecedor não entregue o objeto), o que significa que um orçamento $100 \%$ empenhado não deve ser entendido como "totalmente executado", para fins de análise de custos. Assim, é preciso ter como parâmetro a despesa liquidada: "não resta dúvida de que a informação da despesa liquidada é a que mais se aproxima da definição de custo como o gasto realizado na aquisição de bens ou serviços necessários à produção de outros bens ou serviços". (MACHADO; HOLANDA, 2010, p. 803-804).

Deve-se destacar que são frequentes as associações entre despesa empenhada e a ideia de "despesa executada" como sinônimo de "orçamento executado". Um exemplo desta percepção está presente em um estudo realizado sobre a aplicação dos recursos destinados à pesquisa na UFPB, no qual os autores constatam que "cerca de $22,51 \%$ dos valores recebidos não foram executados e utilizados pelos programas de Pós-Graduação, sendo devolvidos à União no fim do exercício". (REGO; SOUZA, 2019, p. 14). Em seguida, “Destaca-se a execução realizada pela Universidade Federal do Rio Grande do Norte (UFRN), com praticamente $100 \%$ de utilização dos recursos PROAP, bem como a UFPE e a UFBA que também obtiveram bons resultados na execução dos recursos". (REGO; SOUZA, 2019, p. 15).

Contudo, como não é incomum o descumprimento do objeto por parte dos fornecedores, de modo que o estágio da liquidação não se efetive, a despesa empenhada não significa, a rigor, despesa executada integralmente. Os próprios autores do estudo realizado na UFPB reconhecem que o resultado final da execução não pode ser avaliado somente durante a fase inicial da despesa:

Deve-se destacar que a análise dos valores devolvidos no fim do exercício financeiro se refere àqueles empenhados até o dia 31 de dezembro de cada ano, excetuando-se os valores inscritos em Restos a pagar e que serão, ou não, pagos ao longo do ano que se inicia. Tais valores também influenciam o resultado final da execução, e que merece um estudo mais detido, o que foge ao escopo deste trabalho (REGO; SOUZA, 2019, p. 14). 
De modo que é possível que a universidade paraibana tenha realizado uma execução mais efetiva desse orçamento: se a UFPB tiver liquidado mais de $80 \%$ dos valores empenhados, ao tempo que a UFRN tenha liquidado até $60 \%$ dos seus valores.

Portanto, é preciso considerar, sempre, os valores liquidados para fins de uma avaliação mais abrangente. E não considerar somente a liquidação dos empenhos do exercício, mas também a dos valores de exercícios anteriores inscritos em restos a pagar.

\subsection{Vislumbrando o futuro: O SIC}

Um passo importante em direção à apuração de custos foi dado com o surgimento do SIC, o Sistema de Informações de Custos do Governo Federal. Em meio a um processo de convergência com as normas internacionais de contabilidade e visando a promover a melhoria da informação contábil, o SIC foi implantado em 2012, juntamente com uma atualização do SIAFI necessária para adequação ao novo Plano de Contas Aplicado ao Setor Público (PCASP). Contudo, muitas são as dificuldades que se impõem à utilização do SIC e ao seu desenvolvimento como ferramenta gerencial. Em estudo sobre as causas pelo uso (ou não) de sistema de custos pelas IFES brasileiras, realizado entre 2015 e 2016, verificou-se que, das 80 IFES investigadas apenas 4 afirmaram utilizar algum sistema de custos. Dentre as causas da não utilização, 25 foram classificadas como "aguardando o desenvolvimento do SIC"; 17 afirmaram apenas não possuir sistemas de custos; 9 (nove) informaram estar "desenvolvendo plataforma própria"; 5 foram classificadas no grupo "com dificuldades operacionais" e 3 (três) informaram como causa “Não se aplica para a unidade". Concluiu-se que:

embora existam pesquisas de longa data a respeito do tema, é possível reconhecer que há dificuldades na implantação de um sistema de custos no âmbito das IFES, devido à complexidade das atividades, a magnitude do trabalho, o acompanhamento na implantação do sistema e, por fim, de uma cultura de apuração e controle de custos público em todo o território nacional (SANTOS; COSTA; VOESE, 2016, p. 1).

Ressalte-se que mesmo com os avanços trazidos pelo SIC, a apuração de custos via dados do SIAFI continua comprometida devido a questões relacionadas a aspectos quantitativos relativos ao consumo de materiais e à depreciação dos bens, ambas ainda não plenamente contempladas. Entretanto, com a publicação da Portaria no 385 , de 28/11/2018, que instituiu Sistema Integrado de Gestão Patrimonial - SIADS, delineia-se 
um futuro mais promissor quanto ao gerenciamento dos acervos de bens móveis, o que possibilitará, devido à integração com o SIAFI, mensurar custos de maneira automatizada.

\section{As dificuldades enfrentadas pelas propostas de mensuração de custos em IFES}

A contínua apuração e análise de custos favorece a identificação de desperdícios ou de ociosidade. Como custos menores estão associados à ideia de eficiência, vários autores têm afirmado que estes dados podem ser usados para fins de avaliação de órgãos públicos, a despeito das finalidades precípuas das informações sobre custos discutidas no item anterior: controle e tomada de decisão. Alonso (1999) defende que uma adequada avaliação do desempenho dos serviços públicos tem que considerar seus custos. Assim, justifica-se a apuração de custos no setor público em razão de sua "utilização como mecanismo de aferição da eficiência" (REMÍGIO, 2002, p. 72). 0 mesmo entendimento pode ser encontrado no âmbito das IFES, em estudos sobre métodos de apuração de seus custos, em que se afirma que tais métodos podem ser usados "na avaliação da eficiência das universidades" (SILVA; MORGAN; COSTA, 2004, p. 1). Neste sentido, a divulgação de dados sobre custos contribuiria para que a sociedade "possa ter uma percepção mais clara da eficiência e da eficácia dessas Universidades". (REINERT, 2005, p. 87).

No entanto, o uso de dados sobre custos para realização de inferências sobre o desempenho da IFES tem se mostrado problemático, sobretudo quanto a comparações entre as instituições, dada a sua heterogeneidade. É o que se pode observar desde a iniciativa do Tribunal de Contas da União (TCU), que, em 2002, determinou às IFES que incluíssem nos seus relatórios de gestão anuais alguns indicadores, entre os quais o "Custo corrente/aluno equivalente", "que já haviam sido pesquisados [...] tanto por especialistas, quanto por entidades não-governamentais e unidades do MEC, estando presentes em boa parte da literatura brasileira sobre o assunto". (MACHADO, 2004, p. 5051). Na ocasião, as universidades se manifestaram questionando a validade de comparações entre si, por meio dos indicadores propostos:

a dificuldade de comparar as IFES é notória em razão da heterogeneidade e realidades distintas entre elas. Exemplo: uma grande universidade, com graduação, pesquisa e extensão, atuando em várias áreas do conhecimento, não pode ser comparada a uma instituição que oferece, apenas, cursos de graduação, estando voltada quase exclusivamente para a atividade de ensino (UFPE); 
$[\ldots]$

os indicadores não são capazes de captar a complexidade e heterogeneidade das instituições. Além disso, a educação superior não pode ser concebida com um sistema parametrizado que apresente a grandeza típica de um fenômeno (UFRGS) (MACHADO, 2004, p. 53-54).

O próprio TCU reconheceu que "não foi possível a produção de valores médios dos indicadores que pudessem servir de parâmetros nacionais de desempenho". (MACHADO, 2004, p. 53). Contudo, baseado na premissa das vantagens de um sistema de indicadores como ferramenta gerencial e instrumento de fiscalização da gestão, o TCU manteve a inclusão desses dados nos relatórios de gestão, o que tem sido feito até hoje. Conforme Machado (2004), enfatizou-se que não haveria o intuito de estabelecer classificações, mas de acompanhar a evolução do desempenho, o que poderia indicar necessidades de melhorias e a correção de disfunções. Quanto às IFES, a despeito dos questionamentos levantados, também prevaleceu o reconhecimento sobre a importância dos indicadores.

Muitas são as dificuldades, reconhecidas pela literatura, que se impõem às IFES para a mensuração de seus custos. Grande parte delas decorre das peculiaridades que envolvem o seu processo produtivo: o aluno, por exemplo, a depender da perspectiva, pode ser considerado como cliente, produto ou insumo do processo produtivo e, ao tempo, influenciar os resultados institucionais. A diversificação das atividades realizadas pelas IFES, que implica no uso de múltiplos insumos e resulta em diversos produtos, repercute na dificuldade de realizar comparações entre elas. Neste sentido, Peñazola (1999) destaca que:

freqüentemente se confunde custo do ensino com o custo da instituição. Como as instituições, especialmente as universidades, possuem múltiplas funções, o custo total é, obviamente, mais elevado do que o custo do ensino, propriamente dito. A não ser que seja possível distinguir o custo do ensino do custo total, as comparações entre as instituições se tornam distorcidas pois, quanto maior o número de atividades que a universidade desenvolve (ensino, pesquisa, prestação de serviços, extensão), maior o custo total, mesmo que o custo do ensino não seja muito elevado. (PEÑAZOLA, 1999, p. 2)

É sobretudo o compartilhamento de insumos que torna demasiado complexa a apuração de custos nessas instituições. Estruturas como laboratórios, espaços esportivos, museus, teatros, emissoras de rádio, dentre outros, são frequentemente 
compartilhadas entre ensino, pesquisa e extensão. Disto decorre que, para determinar com exatidão o custo exclusivamente do ensino, seria preciso segregá-lo das atividades de pesquisa e extensão. De modo que, como exemplo de um cenário ideal, o valor gasto com a energia elétrica consumida num laboratório onde são realizadas atividades de ensino e várias pesquisas teria que ser dividido, ou rateado, para cada produto gerado. Neste exemplo, a energia elétrica é classificada pela literatura contábil como "custo indireto", pois o seu valor não é passível de alocação direta aos produtos, dependendo sempre de um critério de rateio.

A despeito das complexidades citadas, os pesquisadores têm buscado minimizá-las em suas propostas metodológicas, usando parâmetros de rateio entre as atividades para, assim, obter custos segregados. Geralmente, têm se buscado obter o custo do ensino. Contudo, o estabelecimento de critérios de rateio pode se mostrar problemático. Peter et al (2003), ao buscar identificar e ratear custos por atividade, sugere que:

não sendo encontrada uma relação que vincule o consumo dos recursos com a ocorrência da atividade, estes custos sejam alocados à instituição como um todo, evitando-se assim, rateios arbitrários. Para conseguir este resultado, o modelo sugere que inicialmente sejam levantados os custos das unidades organizacionais, o que já consiste em uma tarefa bastante árdua, uma vez que as universidades não utilizam de forma sistemática a contabilidade de custos (PETER et al, 2003, p. 9)

Assim, o estabelecimento de critérios de rateio pode levar a distorções quando aplicados ao conjunto das IFES, o que compromete a realização de comparações entre os custos dessas instituições.

\subsection{Ressalvas às comparações entre instituições e quanto aos dados utilizados}

Assim, propostas como as de Amaral (2004) e Pereira (2019), que usam a atividade dos docentes como parâmetro para o cálculo do custo do ensino, (levando, à exclusão de até $40,81 \%$ do total do orçamento e não apenas da despesa com pessoal), podem ser adequadas para as grandes universidades, que possuem estruturas maiores e mais diversificadas, mas sua aplicação às instituições menores requer estudos mais aprofundados a fim de verificar o quanto são capazes de evidenciar as outras despesas de custeio com pesquisa e extensão nelas realizadas. 
Ademais, a exclusão de grande parte das despesas vai de encontro às justificativas de apuração de custos que remetem às exigências de transparência dos valores movimentados pelas instituições. Nesse aspecto, a iniciativa do Tribunal de Constas da União (TCU) pode ser considerada mais adequada, pois o indicador Custo corrente/aluno equivalente engloba todas as despesas correntes, deduzindo apenas aquelas que não guardam relação direta com as funções típicas de uma instituição que oferece educação superior ${ }^{6}$, como é o caso dos gastos com aposentadorias e pensões, cuja exclusão é defendida em todas as propostas analisadas neste estudo, exceto a de Peñazola (1999). Neste sentido, entende-se que: "Nas empresas privadas, por exemplo, os empregados são, em sua maioria, aposentados com recursos que não são pagos pelas empresas e, por isso não tem qualquer impacto final nos produtos e serviços oferecidos à sociedade" (REINERT, 2005, p. 49).

\section{Estabelecimento de critérios de análise e questões metodológicas}

A segregação dos gastos entre as atividades de ensino, pesquisa e extensão e a exclusão das despesas com inativos são critérios comuns, presentes na literatura consultada. Contudo, sem dispor de um sistema de custos, uma segregação rigorosa das atividades, que contemple a heterogeneidade das IFES de modo a não incorrer em arbitrariedades, se torna demasiado complexa de operacionalizar para o conjunto dessas instituições.

Por estas razões optou-se por evidenciar todas as despesas liquidadas, sejam aquelas pertencentes ao orçamento do exercício em questão ou de exercício anteriores, sem segregação por atividade, mas classificadas por grupo: Despesa com Pessoal (DP), Despesa com Outras Despesas Correntes de Custeios e de Capital (OCC) e Despesa Total; assim como será evidenciada a participação da despesa com pessoal inativo na DP.

Realizou-se uma pesquisa descritiva e de caráter documental, compreendendo o período de 2012 a 2017 e abrangendo o conjunto das IFES, considerado aquele cujos

\footnotetext{
${ }^{6}$ Ainda assim, a proposta do TCU contém um certo grau de arbitrariedade ao deduzir $65 \%$ das despesas correntes dos hospitais universitários, como padrão para todas as IFES. Contudo, ressalte-se que, em 2008, iniciou-se a desvinculação dessas unidades que, até então, integravam o orçamento das IFES. Com o advento da Portaria $\mathrm{n}^{\circ} 4 / 2008$, do MEC, a maioria dos hospitais passou a dispor de autonomia para gerir seus recursos. 0 processo de desvinculação intensificou-se em 2009, quando os hospitais passaram a incluir as Despesas com Pessoal em sua estrutura de gastos. De modo que, conforme os dados encontrados no decorrer desta pesquisa, o percentual da despesa da ação referente à gestão das unidades hospitalares perante o total da despesa de custeio nunca foi maior que 1,72\%. Fica assim demonstrado que a exclusão proposta pelo TCU tem, hoje, pouco impacto no total do seu indicador.
} 
membros constam como Unidade Orçamentária-UO no SIAFI e que trazem em sua denominação o termo universidade. Assim, o universo pesquisado é composto por 63 instituições. Não estão incluídos os institutos da RFEPT, dado que neles não se oferta apenas a educação terciária e em razão de não ser possível segregar as despesas por nível de ensino.

$\mathrm{O}$ ano inicial foi escolhido pelo fato do novo PCASP ter entrado em vigor em 2012, juntamente com a nova versão do SIAFI, o que provocou uma alteração substancial na estrutura das contas. A escolha de 2017 como ano final deveu-se ao fato do levantamento e da formatação dos dados terem sido realizados antes do final de 2018, motivo pelo qual este ano não pôde ser contemplado.

As informações sobre as despesas foram obtidas por meio da ferramenta Tesouro Gerencial, sistema do governo que extrai as informações diretamente do SIAFI, a fim de produzir relatórios gerenciais. Para esta pesquisa, os dados foram exportados no formato de planilhas eletrônicas e a partir delas foram realizadas análises estatísticas descritivas.

Os dados das matrículas foram extraídos dos relatórios "Sinopses Estatísticas" do Censo da Educação Superior do INEP para a graduação, e do Portal Geocapes da CAPES, para as matrículas da pós-graduação, que somadas retornam os valores que foram utilizados nas análises.

Entende-se que para realizar análises mais criteriosas, o aspecto da heterogeneidade deva ser sempre contemplado. Assim, como a presença de outliers tende a distorcer os resultados do grupo, busca-se analisar valores máximos, mínimos além de variações nas despesas, quando as instituições são agrupadas por volume de gastos realizados, a fim de encontrar padrões mais homogêneos.

\section{Apresentação de Resultados}

A depender da perspectiva adotada, muitas são as análises que se pode realizar a partir dos dados que foram levantados. Contudo, para o que esta pesquisa se propôs, acredita-se que o que está exposto nos resultados a seguir seja suficiente.

\subsection{Análise sobre o volume de despesas das IFES}


SIMÕES, L. R. D; LIMA, M. A. M. Variabilidade das despesas das universidades federais no período de 2012 a 2017

Para uma primeira aproximação com o objeto de pesquisa, a tabela 1 traz os valores das liquidações totais do conjunto das IFES, em valores nominais e corrigidos a preços de dezembro de 2017, pelo IPCA.

Tabela 1 - Despesa total, com Pessoal e com OCC do conjunto das IFES, de 2012 a 2017 (em R\$ mil)

\begin{tabular}{|c|c|c|c|c|c|c|}
\hline & 2012 & 2013 & 2014 & 2015 & 2016 & 2017 \\
\hline \multicolumn{7}{|c|}{ Valores Nominais } \\
\hline Pessoal & 25.715 .030 & 29.397 .6225 & 32.959 .392 & 36.221 .924 & 39.706 .463 & 44.251 .275 \\
\hline $\mathrm{OCC}$ & 11.378 .159 & 13.176 .478 & 8.151 .101 & 7.263 .936 & 7.142 .741 & 7.017 .251 \\
\hline Total & 37.093 .190 & 42.574 .100 & 41.110 .493 & 43.485 .859 & 46.849 .208 & 51.268 .526 \\
\hline \multicolumn{7}{|c|}{ Valores Corrigidos } \\
\hline Pessoal & 35.372 .097 & 38.230 .099 & 40.225 .069 & 40.014 .787 & 40.999 .380 & \\
\hline OCC & 15.651 .133 & 17.135 .333 & 9.947 .957 & 8.024 .555 & 7.375.322. & \\
\hline Total & 51.023 .229 & 55.365 .432 & 50.173 .026 & 48.039 .342 & 48.374 .703 & \\
\hline \multicolumn{7}{|c|}{ Despesa com pessoal ativo e inativo } \\
\hline Ativos & 25.493 .889 & 27.618 .816 & 29.133 .537 & 28.946 .217 & 29.751 .631 & 31.769 .820 \\
\hline Inativos & 9.878 .208 & 10.611 .283 & 11.091 .532 & 11.068 .570 & 11.247 .749 & 12.481 .454 \\
\hline
\end{tabular}

Fonte: Elaboração própria com base nos dados do SIAFI 2012 a 2017

Observa-se que a despesa total praticamente não variou em termos reais (aumento de 0,48\%), quando passou de R \$ 51,02 bilhões, em 2012, para R \$ 51,27 bilhões, em 2017.

Gráfico 1 - Despesa total, com Pessoal e com OCC do conjunto das IFES, de 2012 a 2017 (em R\$)

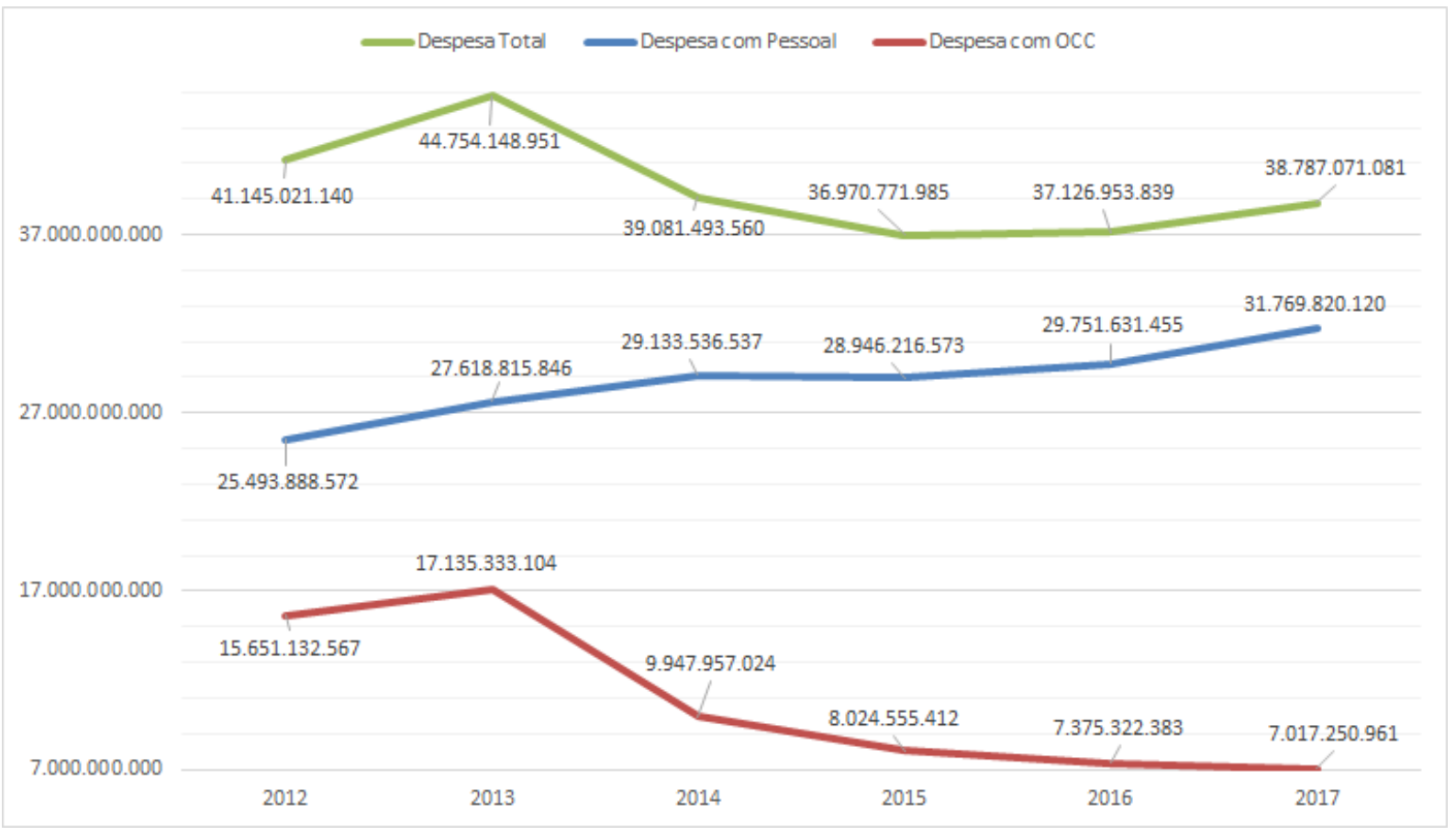

Fonte: Elaboração própria com base nos dados do SIAFI 2012 a 2017 
Percebe-se um crescimento na DP, com uma variação da ordem de $24,62 \%$ e um decréscimo na despesa com OCC, que em 2017 representou apenas 44,84\% dos valores praticados em 2012. Ou seja, houve uma redução de mais de 50\% na despesa com OCC, que seria maior (59,48\%) se o período analisado se iniciasse em 2013.

No que se refere à despesa com inativos, conforme o expoto na Tabela 1, notase um crescimento gradual no período, exceto por 2015. Após uma contínua perda de participação verificada desde 2012, quando detinha 27,93\% da DP, a despesa com inativos atingiu o menor percentual em 2016 (27,43\%), mas voltou a ganhar espaço e atingiu, em 2017, o maior percentual de participação verificado no período: de 28,21\%. Nas universidades mais antigas percentuais acima de 30\% são frequentemente encontrados, enquanto que naquelas criadas recentemente, 100\% da DP é referente apenas aos ativos. 0 percentual máximo atingido individualmente foi de $38,47 \%$, em 2017.

Tabela 2 - Média e desvio-padrão (DsvP) da despesa com pessoal e da despesa com OCC, por grupo de universidades (em R\$ mil).

\begin{tabular}{lcccrrr}
\hline \multicolumn{2}{c}{$\mathbf{2 0 1 2}$} & $\mathbf{2 0 1 3}$ & $\mathbf{2 0 1 4}$ & $\mathbf{2 0 1 5}$ & $\mathbf{2 0 1 6}$ & $\mathbf{2 0 1 7}$ \\
\hline Conjunto das 63 IFES & & & & & \\
\hline Média da DP & 432.100 & 468.116 & 462.437 & 459.464 & 472.248 & 504.283 \\
\hline DsvP da DP & 370.451 & 388.168 & 406.371 & 392.051 & 395.486 & 410.451 \\
\hline Média OCC & 265.273 & 290.429 & 157.904 & 127.374 & 117.069 & 111.385 \\
\hline DsvP OCC & 179.901 & 201.974 & 123.534 & 87.283 & 83.954 & 77.952 \\
\hline Grupo das 30 maiores instituições & & & & & \\
\hline Média da DP & 704.830 & 757.437 & 788.728 & 775.303 & 792.485 & 838.282 \\
\hline DsvP da DP & 338.540 & 348.462 & 370.544 & 356.513 & 358.518 & 366.873 \\
\hline Média OCC & 376.370 & 412.478 & 249.363 & 197.965 & 184.899 & 174.297 \\
\hline DsvP OCC & 189.001 & 220.354 & 126.140 & 77.565 & 76.497 & 71.489 \\
\hline Grupo das 33 menores instituições & & & & & \\
\hline Média da DP & 69.459 & 80.642 & 83.891 & 90.437 & 98.196 & 194.365 \\
\hline DsvP da DP & 67.957 & 76.490 & 80.505 & 81.573 & 86.649 & 95.464 \\
\hline Média OCC & 150.712 & 163.524 & 75.455 & 62.700 & 54.865 & 53.916 \\
\hline DsvP OCC & 72.049 & 61.961 & 35.029 & 29.170 & 20.216 & 18.565 \\
\hline
\end{tabular}

Fonte: Elaboração própria com base nos dados do SIAFI 2012 a 2017

Há grandes diferenças quando as IFES são agrupadas em termos de volume de despesas realizadas: aquelas com liquidações totais acima (30 maiores) e abaixo de $\mathrm{R} \$$ 700 milhões (33 menores) em 2017. No conjunto das 63 IFES, os coeficientes de variação em todos os anos são sempre acima de $80 \%$ para a DP, e sempre próximos de $70 \%$ para a 
despesa com OCC. A segregação em grupos faz tais índices caírem, em ambos os grupos, deixando-os um pouco mais homogêneos.

Percebe-se que, além da redução da despesa com OCC, houve um crescimento maior, proporcionalmente, na DP do grupo das menores instituições, o que indica que os investimentos em pessoal obtiveram maiores resultados posteriormente aos investimentos em OCC.

Tabela 3 - Percentual de participação da despesa com pessoal e com OCC na despesa total, por grupo de universidades.

\begin{tabular}{|c|c|c|c|c|c|c|}
\hline & 2012 & 2013 & 2014 & 2015 & 2016 & 2017 \\
\hline \multicolumn{7}{|c|}{ Conjunto das 63 IFES } \\
\hline Pessoal & 72,61 & 61,71 & 74,55 & 78,29 & 80,13 & 81,91 \\
\hline OCC & 27,39 & 38,29 & 25,45 & 21,71 & 19,87 & 18,09 \\
\hline \multicolumn{7}{|c|}{ Grupo das 30 maiores instituições } \\
\hline Pessoal & 65,36 & 64,92 & 76,18 & 79,76 & 81,09 & 82,82 \\
\hline OCC & 34,64 & 35,08 & 23,82 & 20,24 & 18,91 & 17,18 \\
\hline \multicolumn{7}{|c|}{ Grupo das 33 menores instituições } \\
\hline Pessoal & 49,44 & 50,17 & 68,23 & 72,83 & 76,56 & 78,61 \\
\hline OCC & 50,56 & 49,83 & 31,77 & 27,17 & 23,44 & 21,39 \\
\hline \multicolumn{7}{|c|}{ Apenas as 11 IFES recém-criadas } \\
\hline Pessoal & 34,68 & 35,03 & 57,33 & 64,88 & 71,87 & 74,94 \\
\hline OCC & 65,32 & 64,97 & 42,67 & 35,12 & 28,13 & 25,06 \\
\hline
\end{tabular}

Fonte: Elaboração própria com base nos dados do SIAFI 2012 a 2017

A representatividade do grupo das 30 maiores instituições no total das despesas do conjunto das IFES fez este grupo ser responsável, em média, por 80,95\% do total da DP, 73,41\% da despesa com OCC e 78,71\% da despesa total liquidada. Houve, ao longo do período, uma redução na participação das DP desse grupo no total da DP executado pelo conjunto das IFES, de 82,97\% em 2012 para 79,11\% em 2017; assim como um crescimento na participação despesa com OCC, de 71,62\% em 2012 para 74,28\% em 2017.

Novamente, esses movimentos refletem os investimentos da expansão, concentrados em 2012 e 2013, que impactaram as despesas com OCC, sobretudo das menores universidades. Nos anos seguintes, a queda desses investimentos, em paralelo ao aumento na DP, refletiu-se nos percentuais de participação dos grupos de despesa perante a despesa total, com grande variação ocorrida no grupo das 11 universidades criadas a partir do ano 2000, conforme demonstrado na tabela 3. 
Em análise individualizada, considerando todas as IFES, revelou-se que em 2017, os valores máximo e mínimo de participação da DP na despesa total, foram de $88,39 \%$ e 62,36\%, respectivamente. 0 que significa há casos em que a despesa com OCC representa apenas $11,61 \%$, ou até $37,64 \%$ da despesa total liquidada.

\subsection{Análise sobre a despesa por matrícula.}

Ao dividir a despesa por matrícula, as variações entre as IFES são ponderadas, o que reduz o impacto do volume de recursos movimentados por instituição, conforme exposto na tabela 4. De modo que o grupo das 30 maiores instituições, em termos de montante movimentado, possui outliers que distorcem as médias. No grupo das 30 maiores, por exemplo, a UNIFESP atingiu o valor de R $\$ 59.772,93$ na DP por matrícula em 2017, o que levou sua despesa total por matrícula a $R \$ 68.422,60$ neste ano. A UFPI, por sua vez, apresentou valores muito menores que a média do grupo, com $\mathrm{R} \$ 13.637,88$ na DP por matrícula.

Assim, extremos como esses foram excluídos a fim de reduzir os desviospadrão e coeficientes de variação, num total de 5(cinco) IFES do grupo das maiores e 3(três) do grupo das menores. Ainda assim, nota-se grande variabilidade.

Tabela 4 - Despesa média, desvio-padrão (DsvP), valor máximo e mínimo da despesa com pessoal e da despesa com OCC, por matrícula, por grupo de universidades. Valores corrigidos (em R\$).
2012
2013
2014
2015
2016
2017

\begin{tabular}{lrrrrrr}
\hline Conjunto das 63 IFES & \multicolumn{5}{l}{} \\
\hline Média da DP & 22.616 & 23.913 & 23.749 & 23.374 & 23.242 & 24.263 \\
\hline DsvP da DP & 9.445 & 10.046 & 9.678 & 8.592 & 7.970 & 7.974 \\
\hline Máximo da DP & 59.651 & 65.406 & 64.111 & 59.684 & 54.380 & 59.773 \\
\hline Mínimo da DP & 9.047 & 10.502 & 9.862 & 11.709 & 11.511 & 13.638 \\
\hline Média OCC & 23.246 & 22.159 & 9.918 & 7.684 & 6.634 & 6.107 \\
\hline DsvP OCC & 37.691 & 25.671 & 5.991 & 3.184 & 2.494 & 2.207 \\
\hline Máximo OCC & 276.084 & 173.177 & 40.674 & 21.583 & 15.439 & 13.997 \\
\hline Mínimo OCC & 5.469 & 6.858 & 3.097 & 3.454 & 3.526 & 2.531 \\
\hline Grupo das 25 maiores instituições & & & & & 26.268 \\
\hline Média da DP & 24.895 & 25.801 & 26.321 & 25.423 & 25.688 & 4.508 \\
\hline DsvP da DP & 4.844 & 4.877 & 5.007 & 4.825 & 5.202 & 20.111 \\
\hline Mínimo da DP & 15.092 & 15.663 & 17.373 & 18.728 & 18.453 & 5.441 \\
\hline Média OCC & 13.459 & 14.391 & 8.254 & 6.573 & 6.017 & 1.386 \\
\hline DsvP OCC & 6.883 & 7.291 & 3.427 & 1.975 & 1.447 & 9.631 \\
\hline Máximo OCC & 42.775 & 42.381 & 20.171 & 14.149 & 9.775 & 3.911
\end{tabular}


SIMÕES, L. R. D; LIMA, M. A. M. Variabilidade das despesas das universidades federais no período de 2012 a 2017

\begin{tabular}{lrrrrrr}
\hline Grupo das 30 menores instituições & & & & & \\
\hline Média da DP & 17.384 & 18.471 & 18.573 & 19.149 & 18.998 & 20.415 \\
\hline DsvP da DP & 4.529 & 4.075 & 3.830 & 3.863 & 3.665 & 3.469 \\
\hline Média OCC & 24.520 & 25.188 & 10.289 & 8.136 & 6.723 & 6.340 \\
\hline DsvP OCC & 24.563 & 21.913 & 5.295 & 2.948 & 2.592 & 2.324 \\
\hline
\end{tabular}

Fonte: Elaboração própria com base nos dados do SIAFI 2012 a 2017, Censo INEP e GeoCAPES

A média da despesa total por matrícula (DM) para as 63 IFES atingiu R $\$$ 46.071,43 em 2013, seu valor máximo no período, e o mínimo de $\mathrm{R} \$ 29.876,45$, em 2016, conforme demonstra o gráfico 2.

Gráfico 2 - Média da despesa total por matrícula (em R\$)

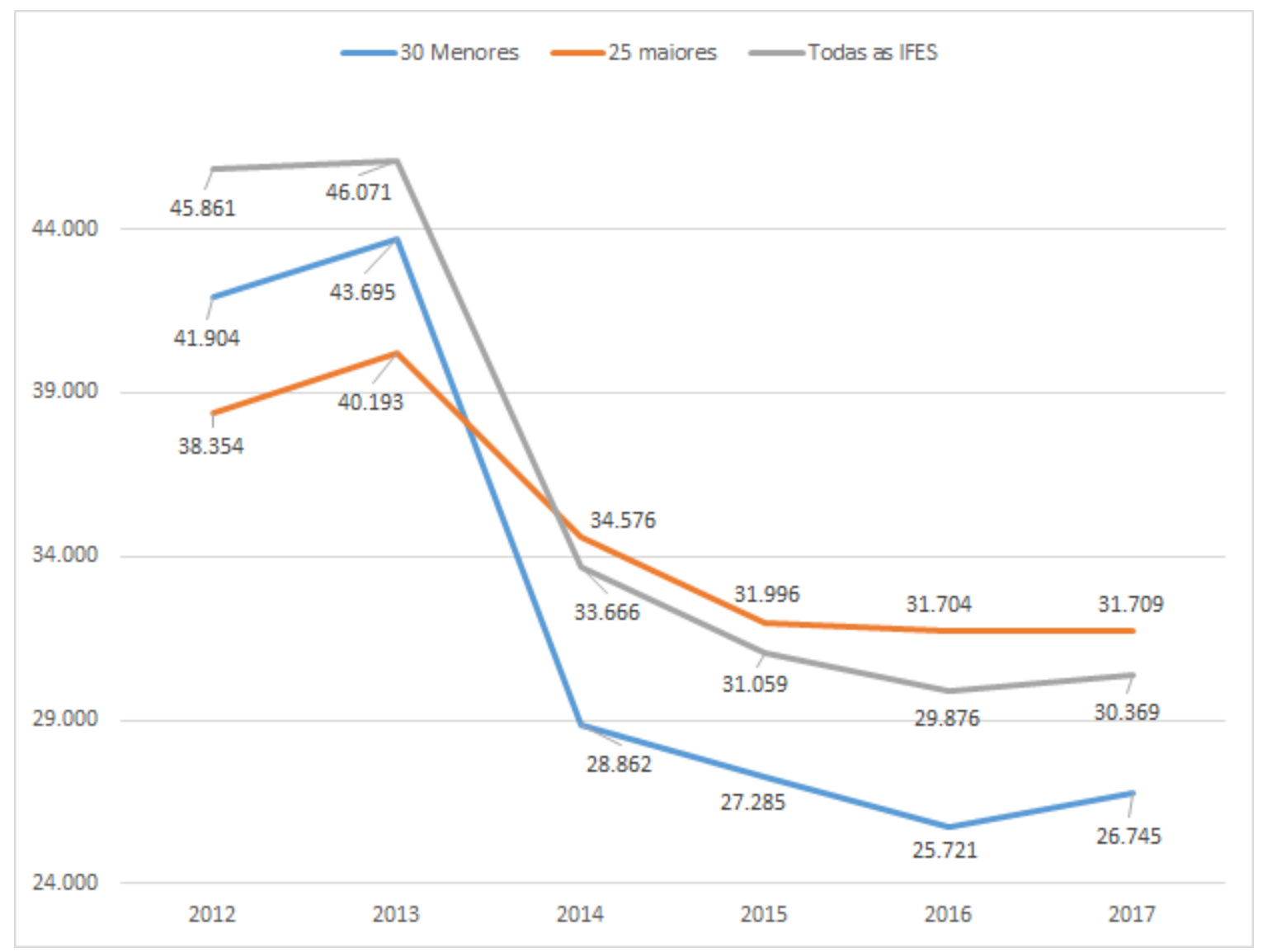

Fonte: Elaboração própria com base nos dados do SIAFI 2012 a 2017, Censo INEP e GeoCAPES

\section{Considerações complementares}

As IFES constituem um grupo heterogêneo que abrange instituições cuja execução da despesa, em 2017, ultrapassou os R \$3,7 bilhões (UFRJ) e instituições que movimentaram menos de R 100 milhões no mesmo período, como a UFSB e a UFOB, um 
número 37 vezes menor. Quando ponderada pelo número de alunos matriculados, a despesa liquidada por matrícula, em 2017, variou de $\mathrm{R} \$ 16.480,39$ (UFMA) a $\mathrm{R} \$ 68.422,60$ (UNIFESP) anuais. Deve-se ressaltar que a UNIFESP se especializou em cursos na área de saúde, que possuem os maiores custos.

Em virtude das variações significativas na execução das despesas, cujas médias distorcidas pela presença de outliers impactam substancialmente os resultados, conclui-se que as análises sobre as despesas das IFES devem sempre considerar a heterogeneidade desse grupo de instituições. Portanto, as implicações da adoção de valores médios de execução para o conjunto das IFES (como o "custo-médio por aluno das IFES") têm pouca representatividade perante a miríade de realidades individuais.

Assim, comparações entre as instituições, para fins de avaliação de seu desempenho quanto aos recursos por elas executados, não devem ser realizadas sem uma avaliação conjunta de suas peculiaridades e de seus resultados.

Espera-se que, com o desenvolvimento do SIC, juntamente com a implantação do SIADS, seja possível mensurar custos, efetivamente segregados por atividade. De modo que, com o levantamento de dados sobre os resultados das atividades das IFES, seja possível avaliar o desempenho dessas instituições quanto ao uso dos recursos orçamentários de que dispõem.

\section{Referências}

ALONSO, M. Custos no Serviço Público. Revista do Serviço Público, Brasília, v. 50, n. 1, p. 37-62, jan./mar. 1999. Disponível em:

$<$ https://revista.enap.gov.br/index.php/RSP/article/view/340>. Acesso em: 02

fevereiro 2019.

AMARAL, N. C. Evolução do custo do aluno das IFES: eficiência? Revista Avaliação -

Revista de Avaliação Institucional da Educação Superior. São Paulo, v. 9, n. 2, p. 115125, jun., 2004. Disponível em: < http://periodicos.uniso.br/ojs/index.php/avaliacao/article/view/1272>. Acesso em: 02 fevereiro 2019.

CHAVES, V. L. J.; AMARAL, N. C. A educação superior no Brasil: os desafios da expansão e do financiamento e comparações com outros países. Revista Educação Em Questão, v. 51, n. 37, jan./abr. 2015. Disponível em:

$<$ https://periodicos.ufrn.br/educacaoemquestao/article/view/7173 >. Acesso em: 02 fevereiro 2019.

CONSELHO NACIONAL DE EDUCAÇÃO; UNESCO. Desafios e perspectivas da educação superior brasileira para a próxima década. Brasília, 2012. Disponível em 


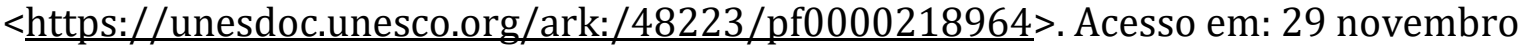
2018.

HENDRIKSEN, E. S.; VAN BREDA, M. F. Teoria da Contabilidade. 5. ed. São Paulo: Atlas, 1999.

MACHADO, N.; HOLANDA, V. B. Diretrizes e modelo conceitual de custos para o setor público a partir da experiência no governo federal do Brasil. Revista de Administração Pública, Rio de Janeiro, v. 44, n. 4, Ago. 2010. Disponível em: < http://bibliotecadigital.fgv.br/ojs/index.php/rap/article/view/6949>. Acesso em: 02 fevereiro 2019.

MACHADO, S. B. Utilização de indicadores de desempenho na avaliação de gestão realizada pelo TCU. 2004. 81f. Monografia (Especialização em Controle Externo) - PósGraduação em Controle Externo, Instituto Serzedello Corrêa do Tribunal de Contas da União, Brasília, 2004.

MAHER, M. Contabilidade de Custos: criando valor para a Administração. Tradução José Evaristo dos Santos. São Paulo: Atlas, 2001.

PEÑALOZA, V. Um modelo de análise de custos do ensino superior. São Paulo NUPES, 1999. Disponível em: < http://nupps.usp.br/downloads/docs/dt9902.pdf > . Acesso em: 28 agosto 2019.

PEREIRA, J. V. A evolução do gasto-médio/aluno e custo-médio/aluno da Rede Federal de Educação Profissional, Científica e Tecnológica. Revista Brasileira de Política e Administração da Educação, v. 35, n. 2, p. 329, ago. 2019. Disponível em: $<$ https://seer.ufrgs.br/rbpae/article/view/vol35n22019.95408>. Acesso em: 28 agosto 2019.

PETER, M. G. A.; MARTINS, E.; PESSOA, M. N. M.; PETER, F. A. Proposta de um sistema de custos para as Universidades Federais Brasileiras fundamentado no Activity Based Costing. Anais da XXVII Reunião Anual da ANPAD, São Paulo, 2003.

REGO, D. L.; SOUSA JR., L. Aplicação dos recursos do PROAP na UFPB: um estudo de caso. Jornal de Políticas Educacionais. V. 13, n. 4. Janeiro de 2019. Disponível em: $<$ https://revistas.ufpr.br/jpe/article/download/62468/37499 >. Acesso em: 08 julho 2019.

REINERT, C. Metodologia para apuração de custos nas IFES brasileiras. Dissertação (Mestrado em Administração). 2005. 91f. Pós-Graduação em Administração. Universidade Federal de Santa Catarina, Florianópolis, 2005.

REMÍGIO, H G. Custos no serviço público - um modelo aplicado ao custeio dos processos judiciais. 2002. 167f. Dissertação. (Mestrado em Contabilidade). Programa Multiinstitucional e inter-Regional de Pós-graduação em Ciências Contábeis. Brasília, 2002. 
RISTOFF, D. 0 novo perfil do campus brasileiro: uma análise do perfil socioeconômico do estudante de graduação. Avaliação (Campinas) [online]. vol.19, n.3, pp.723-747, novembro 2014. Disponível em <http://dx.doi.org/10.1590/S141440772014000300010>. Acesso em: 29 novembro 2018.

SANTOS, M. R.; COSTA, F.; \& VOESE, S. B. Causas da (não) utilização de sistemas de apuração de custos pelas instituições federais de ensino superior. In: Anais do Congresso Brasileiro de Custos-ABC.2016.

SILVA, C. A. T.; MORGAN, B. F.; COSTA, P. de S. Apuração do Custo de Ensino por Aluno: aplicação a uma Instituição Federal de Ensino Superior. In: Encontro Nacional dos Programas de Pós-Graduação em Administração, 2004, Curitiba/PR: ENANPAD, 2004.

UNESCO. Política de mudança e desenvolvimento no ensino superior. Tradução e revisão de Laura A. Ferrantinni Fusaro. Rio de Janeiro: Garamond, 1999. 

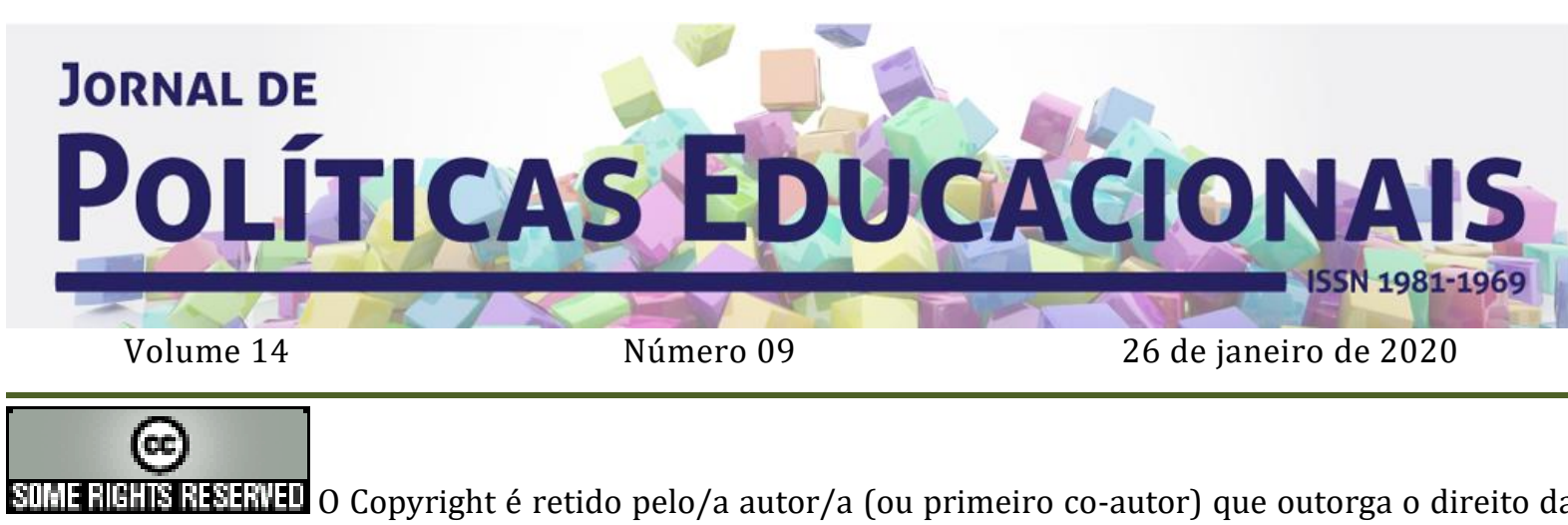

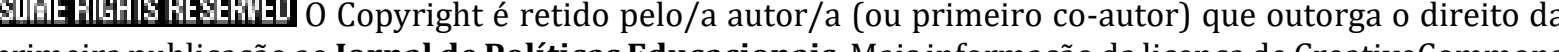
primeira publicação ao Jornal de Políticas Educacionais. Mais informação da licença de CreativeCommons encontram-se em http://creativecommons.org/licenses/by-nc-nd/2.5. Qualquer outro uso deve ser aprovado em conjunto pelo/s autor/es e pelo periódico.

JoRnal DE PolíticAs EdUCACIONAIS é uma publicação do Núcleo de PolíticasEducacionaisdo Setor de Educação da Universidade Federal do Paraná - NuPE/UFPR, em consórcio com a Linha de Pesquisa em Políticas Educacionais do Programa de Pós-Graduação em Educação - PPGE/UFPR, que aceita colaboração, reservando-se o direito de publicar ou não o material espontaneamente enviado à redação. As colaborações devem ser enviadas ao NuPE/UFPR, conforme orientações contidas nas páginas do periódico na internet: http://revistas.ufpr.br/ipe.

Indexação:

BBE - Biblioteca Brasileira de Educação (MEC/INEP)

Clase (Base de Datos Bibliográfica de Revistas de Ciencias Sociales y Humanidades)

Diadorim - Diretório de Política de Acesso Aberto das Revistas Científicas Brasileiras (IBICT)

Google Scholar

Index Copernicus

Portal de Periódicos (CAPES)

SER - Sistema Eletrônico de Revistas da Universidade Federal do Paraná (SER/UFPR)

Sumários de Revistas Brasileiras (FUNPEC-RP)

DRJI - Directory of Research Journals Indexing

(Periódico integralmente disponível apenas em via eletrônica)

Jornal de Políticas Educacionais / Núcleo de Políticas Educacionais da Universidade Federal do Paraná NuPE/UFPR - v.1, n. 1 (1ํㅗ semestre de 2007) - Curitiba: NuPE/UFPR.

Volume 14, número 09 - Janeiro de 2020

ISSN 1981-1969

1. Educação - Periódicos. 2. Política Educacional - Periódicos. I. NuPE/UFPR

Comitê Editorial:

Elisângela Scaff (UFPR)

Daniela de Oliveira Pires (UFPR)

Conselho Editorial:

Andréa Barbosa Gouveia (UFPR - Brasil), Cesar Tello (Universidad Nacional Tres Febrero, Argentina), Fernanda Saforcada (Universidad de Buenos Aires - UBA - Argentina), Gladys Beatriz Barreyro (USP Brasil), Gustavo Enrique Fischman, (Arizona State University - USA), Jefferson Mainardes (UEPG - Brasil), João Ferreira de Oliveira (UFG - Brasil), Juca Gil (UFRGS - Brasil), Luiz Souza Júnior (UFPB - Brasil), Ney 
SIMÕES, L. R. D; LIMA, M. A. M. Variabilidade das despesas das universidades federais no período de 2012 a 2017

Cristina Monteiro de Oliveira (UFPA - Brasil), Nicolás Bentancur, (Universidad de la República de Uruguay), Robert Verhine (UFBA - Brasil), Rosana Cruz (UFPI - Brasil), Rubens Barbosa Camargo (USP - Brasil), Sebastián Donoso Díaz (Universidad de Talca - Chile), TheresaAdrião (UNICAMP - Brasil), Vera Peroni (UFRGS - Brasil).

Créditos e Agradecimentos:

Revisão de Língua Portuguesa, Abstract e Resumen: PROGRAMA DE APOIO ÀS PUBLICAÇÕES CIENTÍFICAS PERIÓDICAS DA UFPR

Arte e diagramação: TIAGO TAVARES (iagotav@gmail.com)

Jornal de Políticas Educacionais

Universidade Federal do Paraná

Setor de Educação

Núcleo de Políticas Educacionais - NuPE/UFPR

Avenida Sete de Setembro, 2645

$2^{\circ}$ andar, Sala 213

80.230-010 - Curitiba - PR - Brasil

Tel.: 41-3535-6264

jpe@ufpr.br

http://revistas.ufpr.br/jpe 